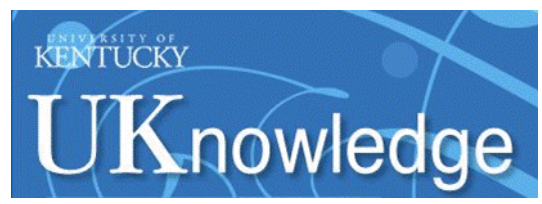

University of Kentucky

UKnowledge

2-8-2018

\title{
Muscle Activity during Maximal Isometric Forearm Rotation Using a Power Grip
}

Joseph Scott Bader

University of Kentucky, jsbader@gmail.com

Michael R. Boland

University of Kentucky, michael@handsurgeon.co.nz

Desney Greybe

University of Auckland, New Zealand

Arthur J. Nitz

University of Kentucky, arthur.nitz@uky.edu

Timothy L. Uhl

University of Kentucky, tluhl2@uky.edu

See next page for additional authors

Follow this and additional works at: https://uknowledge.uky.edu/cbme_facpub

Part of the Biomedical Engineering and Bioengineering Commons, Orthopedics Commons, Rehabilitation and Therapy Commons, and the Surgery Commons

Right click to open a feedback form in a new tab to let us know how this document benefits you.

\section{Repository Citation}

Bader, Joseph Scott; Boland, Michael R.; Greybe, Desney; Nitz, Arthur J.; Uhl, Timothy L.; and Pienkowski, David A., "Muscle Activity during Maximal Isometric Forearm Rotation Using a Power Grip" (2018). Biomedical Engineering Faculty Publications. 21.

https://uknowledge.uky.edu/cbme_facpub/21

This Article is brought to you for free and open access by the Biomedical Engineering at UKnowledge. It has been accepted for inclusion in Biomedical Engineering Faculty Publications by an authorized administrator of UKnowledge. For more information, please contact UKnowledge@lsv.uky.edu. 


\section{Muscle Activity during Maximal Isometric Forearm Rotation Using a Power Grip \\ Digital Object Identifier (DOI)}

https://doi.org/10.1016/j.jbiomech.2017.12.011

Notes/Citation Information

To be published in Journal of Biomechanics.

(c) 2017 Elsevier Ltd. All rights reserved.

(c) 2017. This manuscript version is made available under the CC-BY-NC-ND 4.0 license

http://creativecommons.org/licenses/by-nc-nd/4.0/

The document available for download is the authors' post-peer-review final draft of the article.

\section{Authors}

Joseph Scott Bader, Michael R. Boland, Desney Greybe, Arthur J. Nitz, Timothy L. Uhl, and David A. Pienkowski 


\section{Muscle Activity During Gripping Forearm Rotation}

Joseph Bader ${ }^{1}$, Michael R. Boland ${ }^{2,3,4}$, Desney Greybe ${ }^{4}$, Arthur Nitz ${ }^{5}$, Timothy Uhl ${ }^{5}$, David Pienkowski ${ }^{1,2}$

1. Orthopaedic Biomechanics Laboratory, Center for Biomedical Engineering, University of Kentucky, Lexington, Kentucky.

2. Department of Orthopaedic Surgery, University of Kentucky Medical Center, Lexington, Kentucky.

3. Hand Institute, Glenfield, Auckland, New Zealand.

4. Auckland Bioengineering Institute, University of Auckland, Auckland, New Zealand.

5. Department of Rehabilitation Sciences, University of Kentucky, Lexington, Kentucky.

Submitted as an Original Article to the

Journal of Biomechanics, 2016

Address correspondence to:

Michael R. Boland

Hand Institute, 212 Wairau Road, Glenfield,

Auckland 0627, New Zealand.

Email: michael@handsurgeon.co.nz

Phone: +6494433469

Keywords: activation; electromyography; forearm; muscle; pronation; supination.

Word count: 3362 


\section{Abstract}

2 This study aimed to provide quantitative activation data for muscles of the forearm during

3 pronation and supination while performing a power grip. Electromyographic data was collected

4 from 15 forearm muscles in 11 subjects, while the subjects performed maximal isometric

5 pronating and supinating efforts in nine positions of forearm rotation. Biceps brachii was the

6 only muscle with substantial activation in only one effort direction. All other muscles showed

7 considerable muscle activity when both pronating and supinating. Brachialis, brachioradialis,

8 flexor carpi radialis, palmaris longus, pronator quadratus and pronator teres were significantly

9 more active when pronating the forearm. Abductor pollicis longus, biceps brachii and supinator

10 were significantly more active when supinating. This data highlights the importance of including

11 muscles additional to the primary forearm rotators in a biomechanical analysis of forearm

12 rotation. Doing so will further our understanding of forearm function and lead to the improved

13 treatment of forearm fractures, trauma-induced muscle dysfunction and joint replacements. 


\section{Introduction}

16 In 1956, Sterling Bunnell described the upper extremity as a virtuosity of motion to place the

17 hand in space (Bunnell, 1956). It has subsequently been described as a multi-grasp, unspecialised

18 organ, where the entire upper limb is designed to give maximum mobility to its end organ, the

19 hand (Rabischong, 2014). While this lack of specialised function allows versatility, it also makes

20 studying the function of separate upper limb components difficult.

21 The ability to grip an object and rotate forcefully is a major function of the forearm/wrist/hand

22 complex. Yet, of the upper limb's many functions, the generation of pronosupination torque that

23 can be transmitted to the hand is the most poorly understood (Matsuoka et al., 2006). Forearm

24 torque occurs about an axis that passes through the ulnar head distally and the radial head

25 proximally (Matsuki et al., 2010; Nakamura et al., 1999). Consequently, healthy forearm rotation

26 requires a normal ulna, ulnar head, radius and radial head and depends on normal neuromuscular

27 function (Hagert, 1992).

28 Injury and dysfunction of the forearm is very common, with $15 \%$ of all fractures occurring at the

29 distal radius (Bronstein et al., 1997). One in ten distal radius fractures results in ulnar-sided wrist

30 pain and dysfunction at the distal radioulnar joint (DRUJ) (Geissler et al., 1996). Suboptimal

31 treatments for distal radius fractures have also been associated with significant complications,

32 such as radioulnar impingement and DRUJ instability (Ishii et al., 1998). Improved treatment for

33 these conditions, especially those involving the DRUJ, requires an understanding of the forces to

34 which the distal radius and ulnar head are exposed. In the upper limb, muscles are the major

35 contributor to those loads. Understanding muscle function is thus a key part of understanding

36 forearm mechanics. 
37 Brand provided a unique understanding of musculotendon mechanics at the wrist (Brand and

38 Thompson, 1981). Similar studies have been performed for the elbow (Murray et al., 2000).

39 Mathematical models (Amis et al., 1979; Garner and Pandy, 2001; van der Heijden and Hillen,

40 1996; Werner and An, 1994) and mechanical joint simulators (Gofton et al., 2005; Gordon et al.,

41 2006; Haugstvedt et al., 2001; Werner et al., 1996) have been used to investigate forces in the

42 distal forearm. However, the way in which muscles contribute to forearm rotation has not been

43 clearly established. Consequently, most of these methods have incorporated only a few forearm

44 muscles, so that the accuracy of the models is questionable. It is widely accepted that the biceps

45 brachii, supinator, pronator quadratus and pronator teres muscles are predominantly responsible

46 for forearm pronation and supination (Basmajian and De Luca, 1985; Haugstvedt et al., 2001;

47 O'Sullivan and Gallwey, 2005; Winters and Kleweno, 1993). Yet, many other muscles cross the

48 forearm's axis of rotation. Therefore, while their primary functions may be at the elbow, wrist or

49 hand, these muscles could have secondary roles in forearm rotation.

50 Electromyography (EMG) is a useful tool for investigating muscle function. To date, relatively

51 few studies have examined the activation of upper limb muscles during forearm rotation. The

52 data that does exist is limited primarily to biceps brachii, brachialis and

53 brachioradialis (Basmajian and Latif, 1957; Boland et al., 2008; de Sousa et al., 1961; Naito et

54 al., 1998; Naito et al., 1995). Knowledge of muscle activity is essential to understanding muscle

55 function and joint loading during pronation and supination. The purpose of this study was to

56 provide quantitative EMG data for muscles of the forearm during a simple gripping, forearm

57 rotation task

58 Methods

59 Study Design 
60 Institutional Review Board approval was gained for a laboratory study of EMG muscle activity

61 in normal adults during gripping and forearm rotation. Subjects were examined by a physician to

62 ensure that no forearm or wrist pathology existed and excluded if they had prior

63 forearm/wrist/elbow surgery or injury, arthritis involving the elbow or wrist, neurologic

64 disorders, or aversion to needles. Fifteen forearm muscles were studied using fine-wire

65 electrodes. To prevent electrode interference, the study was divided into four sub-studies (table

66 1). The right forearms of 11 subjects were used in each, with some subjects volunteering for

67 more than one sub-study. Ideally, all the EMG data would be obtained from the same 11

68 subjects, however this was not feasible.

69 Muscles were included based on the following criteria: 1) muscles known to primarily function

70 in forearm rotation; 2) muscles that cross the longitudinal axis of the forearm and therefore have

71 a potential role in DRUJ loading and 3) muscles acting across the elbow that could potentially

72 contribute to forearm pronosupination torque (Buchanan et al., 1989; van Zuylen et al., 1988).

73 The following 15 muscles were analysed: abductor pollicis longus (APL), biceps brachii (BB),

74 brachialis (BRA), brachioradialis (BRAR), extensor carpi radialis brevis (ECRB), extensor carpi

75 radialis longus (ECRL), extensor carpi ulnaris (ECU), extensor indicis proprius (EIP), extensor

76 pollicis longus (EPL), flexor carpi radialis (FCR), flexor carpi ulnaris (FCU), palmaris

77 longus (PL), pronator quadratus (PQ), pronator teres (PT) and the supinator (SUP).

\section{$78 \quad$ Experimental Protocol}

79 The muscles of interest were isolated anatomically using published guidelines (Perotto, 1994).

80 Two sterile, bipolar, Teflon-insulated, $50 \mu \mathrm{m}$ fine-wire electrodes (California Fine Wire Co.,

81 Grover Beach, CA) with 3-5 mm exposed tips were inserted $1 \mathrm{~cm}$ apart in the muscle of

82 interest using a two-needle, sterile insertion technique (Kelly et al., 1997). A grounding surface 
83 electrode was placed on the acromion. For each muscle, a five second baseline data set was

84 collected with the subject's arm relaxed, followed by a maximal voluntary isometric

85 contraction (MVIC) designed to elicit maximal activation in the relevant muscle (Kendall et al.,

86 2005). Each MVIC was performed three times and held for five seconds with a two minute rest

87 interval between trials.

88 The experimental setup is shown in Figure 1. Trials were performed with subjects standing and

89 gripping the handle of a dynamometer (BTE Technologies, Hanover, MD). The procedure was

90 standardised by: adjusting the height of the dynamometer so that the subject's forearm was

91 horizontal and their elbow was flexed at 90 (Bechtel and Caldwell, 1994; Buchanan et al.,

92 1989); placing an abduction pillow under the upper arm; marking the foot position and

93 maintaining it between trials.

94 The handle of the dynamometer was randomly placed in one of nine positions: neutral, $25^{\circ}, 50^{\circ}$,

$9575^{\circ}$ and maximum pronation and supination (N, P25, P50, P75, Pmax, S25, S50, S75 and Smax).

96 The maximum pronation and supination positions were measured using a protractor (Craftsman

97 Tools, Sears Brands LLC., Hoffman Estates, IL). Three times in each position, the subject

98 gripped the handle of the dynamometer and pronated the forearm with as much force as was

99 comfortably possible for five seconds. The subject repeated the three trials while exerting a

100 maximal supinating effort. These tasks resulted in a total of 54 pronation-supination trials per

101 subject. A two minute rest interval was used between trials to reduce fatigue effects (Bigland-

102 Ritchie et al., 1983; Taylor and Gandevia, 2008). The effects of muscle fatigue and order bias

103 were also reduced by employing a Latin Squares sequence design to assign the angles used for

104 each subject.

105 Data Analysis 
106 The EMG data was collected at $2000 \mathrm{~Hz}$ using a portable Myopac amplifier (Run Technologies,

107 Mission Viejo, CA) and stored on a personal computer. A digital band-pass filter of $10-1000$

$108 \mathrm{~Hz}$ was applied to the raw EMG signal prior to full wave rectification. A linear envelope was

109 obtained from the rectified data using a 2nd order Butterworth low-pass filter with a cutoff

110 frequency of $5 \mathrm{~Hz}$. Finally, the data was smoothed using a root-mean-square (RMS) algorithm

111 with a time constant of $20 \mathrm{~ms}$. The average baseline resting recording was subtracted from all

112 EMG data.

113 The peak RMS values were averaged across the three trials for each forearm position and effort

114 direction. These were then normalised to the largest RMS value observed for the given muscle. If

115 a larger RMS value was recorded in a trial rather than during the MVICs, this was used to

116 normalise the EMG data. The normalised EMG data for each muscle, forearm position and effort

117 direction was then averaged across the 11 subjects. The data was processed using Datapac 5

118 software (Run Technologies, Mission Viejo, CA) and Matlab 7.0.1 (The Mathworks, Natick,

119 MA).

120 A repeated measures ANOVA was used to compare the normalised EMG data obtained from

121 each muscle as a function of forearm position and effort direction. Individual differences were

122 determined by post-hoc analyses using the Newman-Keuls test. The threshold for significance

123 was set at 0.05 for this study.

\section{Results}

125 Figures 2 and 3 show the normalised muscle activity recorded for each muscle during maximal 126 pronating and supinating efforts in each of the forearm positions. The BB was the only muscle 127 that, in every forearm position, was significantly more active when supinating than pronating. 
128 All other muscles showed substantial activation during both pronating and supinating efforts.

129 When considered over all nine forearm positions, the APL and SUP were significantly more

130 active when supinating than pronating (table 2). However, the difference was not significant at

131 any individual forearm position. The EPL tended to be more active when supinating with the

132 forearm in a supinated position, but this difference was also non-significant.

133 The PQ and PT were significantly more active when pronating than supinating in every forearm

134 position. The BRAR, FCR and PL were also significantly more active when pronating with the

135 arm in a supinated position. Over all nine forearm positions, the BRA and ECRL were

136 significantly more active during pronating than supinating (table 2). However, this difference

137 was not significant at any individual position and, particularly for ECRL, the actual difference in

138 activation was negligible.

139 The remaining muscles, the ECRB, ECU, EIP and FCU, had no significant difference in

140 activation between pronating and supinating. However, the ECU and FCU tended to be more

141 active when supinating with the arm in a pronated position and pronating with the arm in a

142 supinated position. Conversely, the EIP tended to be more active when pronating with the arm in

143 a pronated position and supinating with the arm in a supinated position.

144 Tables 3 and 4 compare the relative activations between muscles, showing the muscles that were

145 most and least active when pronating and supinating in each forearm position. When compared

146 between muscles, the ECU, PL, PQ and PT were the most active muscles during pronating

147 efforts (table 3). The PQ was the most active muscle when the forearm was in a pronated

148 position, while the PL was the most active when the forearm was in a supinated positon. The PT

149 was the second most active muscle in most forearm positions. The BB was the least active

150 muscle when pronating, throughout the range of forearm rotation. The FCU was one of the least 
151 active muscles, particularly with the arm in a pronated position, while the EPL was one the least

152 active muscles with the arm in a supinated position. The BRA and BRAR were also two of the

153 least active muscles when pronating, particularly with the forearm in a pronated position.

154 When supinating, the APL, BB, ECU and SUP were the most active muscles (table 4). ECU was

155 the most active muscle with the forearm in a pronated position, while APL and BB were the most

156 active with the forearm in a supinated position. The SUP was the most active muscle when the

157 forearm was in a neutral position and was one of the three most active muscles throughout the

158 range of forearm rotation. The BRA and PT were amongst the least active muscles throughout

159 the range of forearm rotation. The PQ was also amongst the least active in most forearm

160 positions and BRAR was amongst the least active muscles with the arm in a supinated position.

\section{Discussion}

162 Muscle activity is essential for understanding muscle function and predicting joint loads during

163 forearm pronation and supination. To date, relatively few studies have examined activation of

164 upper limb muscles during forearm rotation. Previously published EMG data is limited primarily

165 to the BB, BRA and BRAR (Basmajian and Latif, 1957; Boland et al., 2008; de Sousa et al.,

166 1961; Naito et al., 1998; Naito et al., 1995), with a few studies also including the ECRB, PQ, PT

167 or SUP (Basmajian and Travill, 1961; Gordon et al., 2004; O'Sullivan and Gallwey, 2002). This

168 study presents activation data for 15 upper limb muscles during maximal pronation and

169 supination efforts throughout the range of forearm rotation. This data provides insight into the

170 secondary roles of muscles that cross the forearm's axis of rotation and can be applied to future

171 mathematical models of the forearm and DRUJ. 
172 It is widely accepted that the PQ and PT are primarily responsible for pronating the forearm,

173 while the BB and SUP are the primary forearm supinators (Basmajian and De Luca, 1985;

174 Haugstvedt et al., 2001; O'Sullivan and Gallwey, 2005; Winters and Kleweno, 1993). The EMG

175 data recorded in the present study supports those observations. These muscles were activated at

$17645-68 \%$ of their maximum throughout the range of motion during forearm pronation (the PQ and

177 PT) and supination (the BB and SUP). They were amongst the most active muscles in each

178 position of forearm rotation. The $\mathrm{BB}, \mathrm{PQ}$ and $\mathrm{PT}$ were also the only muscles with significantly

179 greater muscle activation during pronation or supination in all forearm positions. This data

180 confirms the prominence of the BB, PQ, PT and SUP during forearm rotation.

181 However, arguably the most striking feature of the data, evident in figures 2 and 3 , is the

182 considerable co-contraction observed. The BB was the only muscle to show meaningful

183 activation for only one direction of forearm rotation. All other muscles, including those that are

184 considered primary supinators and pronators, showed considerable activation regardless of the

185 movement direction. In particular, the SUP, so named due to its role as a primary supinator of the

186 forearm, showed almost the same level of activation during maximal pronation (31-49\%) as it

187 did during maximal supination (46-54\%). The ECU was similarly active when pronating and

188 supinating (34-61\%) and was one of the most active muscles in both effort directions. The PQ

189 and PT were significantly more active when pronating but still showed activation of up to $29 \%$

190 while supinating. This co-contraction during resisted forearm rotation has been shown for the

191 BB, BRA and BRAR (Basmajian and Latif, 1957; Boland et al., 2008; Naito et al., 1998; Naito

192 et al., 1995), and when maximally pronating and supinating for the ECRB, PQ and SUP (Gordon

193 et al., 2004; O'Sullivan and Gallwey, 2002). The level of co-contraction observed in this study

194 would likely be reduced if pure forearm rotation were achieved. However, forearm rotation is 
195 difficult to isolate from gripping (or wrist bracing) and, functionally, forearm rotation will 196 usually accompany the gripping of an object.

197 In addition to the BB, PQ, PT and SUP, several other muscles were notably more active during 198 pronating (the BRA, BRAR, FCR and PL) or supinating (the APL) efforts. The APL is a muscle 199 primarily responsible for abduction and extension of the thumb (Cooney et al., 1985; Drake et 200 al., 2005; Thompson and Netter, 2002). In this study, it was also the most active muscle in the 201 forearm during supination when the arm was at S25 and was amongst the most active at all other 202 positions. Overall, the APL was significantly more active when supinating than it was when 203 pronating. The primary roles of BRA and BRAR are to flex the elbow (Drake et al., 2005;

204 Thompson and Netter, 2002). The BRA was significantly more active during pronation than 205 supination, an observation consistent with previous research (Naito et al., 1998; Naito et al., 206 1995). Due to its attachment site on the ulna, the BRA cannot participate in forearm rotation by 207 directly moving the radius. If its contribution extends beyond bracing the elbow, that 208 contribution will be through varus-valgus and flexion movement of the ulna. Previous research 209 has reported the BRAR to be more active during pronation than supination (Boland et al., 2008; 210 Jamison and Caldwell, 1993; Naito et al., 1998; Naito et al., 1995), although there is some 211 indication its activity depends on the forearm's position (Basmajian and De Luca, 1985). In this

212 study, activation of the BRAR was only significantly greater when pronating with the forearm in 213 a supinated position. Its activation was not significantly different when the forearm was in a 214 pronated position. The primary role of the FCR is to flex and radially deviate the wrist (Brand 215 and Hollister, 1993; Drake et al., 2005; Thompson and Netter, 2002). Like the BRAR, the FCR 216 was significantly more active when pronating than supinating, but only when the arm was in a 217 supinated position. Palmaris longus acts primarily as a wrist flexor (Brand and Hollister, 1993; 
218 Drake et al., 2005; Thompson and Netter, 2002). In this study, it was significantly more active

219 when pronating than supinating in all forearm positions except those from mid to full pronation.

220 With the forearm in a supinated position, it was more active than any other muscle. Clearly,

221 muscles beyond the primary forearm pronators and supinators should be included in any analysis

222 of forearm rotation. Further research is necessary to understand whether these additional muscles

223 are involved agonistically or antagonistically. Those muscles that cross the wrist (the APL, FCR

224 and PL) may assist in the application of torque to the handle. Alternatively, they may act to brace

225 the wrist and better facilitate transfer of the torque generated by the primary forearm rotators to

226 the hand. The EMG data presented in this paper will be valuable to furthering that research.

227 There are several limitations that need to be considered when interpreting the data collected in

228 this study. Crosstalk is an issue that can affect EMG data and is a particular concern in the

229 forearm, given the close proximity of muscles. Fine-wire electrodes, as used in this study,

230 substantially reduce crosstalk relative to surface electrodes (Solomonow et al., 1994). They were

231 also necessary to record the activity of deep muscles. However, while muscle force is related to

232 the number of activated motor units, muscles are not activated homogeneously (van Zuylen et

233 al., 1988). The activity recorded by an electrode (especially fine-wire) may not accurately

234 represent the activity of the muscle as a whole. This may partially explain the considerable inter-

235 individual variability observed in this study. While these limitations are problematic, they are

236 difficult to overcome in a study of this kind. In future research, it may be valuable to use high

237 density EMG arrays to evaluate forearm muscle activity during pronation and supination (Rojas-

238 Martínez et al., 2012). With 23 upper limb muscles attaching in the forearm and only one degree

239 of freedom (pronation-supination), the forearm is a heavily over-defined system. It may be that

240 different individuals employ different activation strategies to achieve forearm rotation. 
241 Accounting for those activation strategies could reduce the variability observed in this study for

242 individual muscle activations. Finally, upper limb posture can affect forearm rotation (Funk et

243 al., 1987; Gielen and van Zuylen, 1986; O'Sullivan and Gallwey, 2002; Winters and Kleweno,

244 1993) and the mechanical advantage of muscles can change with the external axis of rotation

245 (Carson et al., 2000). Therefore, the data presented in this paper is specifically applicable to

246 gripping forearm rotation with the elbow flexed at $90^{\circ}$ and a neutral wrist. Further research is

247 necessary to determine muscle activity during pronation and supination with the upper limb in 248 alternative postures.

249 In conclusion, this paper presents the muscle activation data for 15 upper limb muscles during 250 maximal gripping pronation and supination, in nine positions of forearm rotation. Consistent 251 with literature, the primary forearm pronators and supinators, the BB, PQ, PT and SUP, were all 252 significantly more active in their respective effort directions. The APL, BRA, BRAR, FCR and 253 PL were also significantly more active in one effort direction than the other. With the exception 254 of BB, significant co-contraction was observed for all muscles, regardless of the effort direction. 255 This information is important for understanding joint loads in the forearm and will be 256 particularly valuable when modelling forearm biomechanics. Most muscles with attachments in 257 the forearm are active during resisted forearm rotation and will contribute to the loads 258 experienced at the DRUJ. Incorporating their activity into future biomechanical analyses will 259 provide more accurate estimates of forearm joint loads and facilitate advances in the treatment of 260 forearm fractures, trauma-induced muscle dysfunction and joint replacement implants and 261 techniques. 


\section{Acknowledgements}

264 This work was partially funded by the University of Kentucky Department of Orthopaedic

265 Surgery. The authors would like to thank Dr Joseph Stone, MD, for performing the examination

266 of participants prior to their inclusion in this study.

267 Conflict of interest statement

268 There are no financial or personal conflicts of interest with respect to the research, authorship,

269 and/or publication of this article. 


\section{Reference list}

271 Amis AA, Dowson D, Wright V, Miller JH. The derivation of elbow joint forces, and their relation 272 to prosthesis design. Journal of Medical Engineering \& Technology. 1979, 3: 229-34.

273 Basmajian JV, De Luca CJ. Muscles alive - their functions revealed by electromyography, 5th 274 edn. Baltimore, Maryland, Williams and Wilkins, 1985.

275 Basmajian JV, Latif A. Integrated actions and functions of the chief flexors of the elbow: A 276 detailed electromyographic analysis. Journal of Bone and Joint Surgery, American $277 \quad$ Volume. 1957, 39: 1106-18.

278 Basmajian JV, Travill A. Electromyography of the pronator muscles in the forearm. Anatomical 279 Record. 1961, 139: 45-9.

280 Bechtel R, Caldwell GE. The influence of task and angle on torque production and muscle activity at the elbow. Journal of Electromyography and Kinesiology. 1994, 4: 195-204.

Bigland-Ritchie B, Johansson R, Lippold OCJ, Woods JJ. Contractile speed and emg changes during fatigue of sustained maximal voluntary contractions. Journal of Neurophysiology. 1983, 50: 313-24.

Boland MR, Spigelman T, Uhl TL. The function of brachioradialis. Journal of Hand Surgery (American Volume). 2008, 33A: 1853-9. Book, 1993.

Brand PW, Thompson DE. Relative tension and potential excursion of muscles in the forearm and hand. Journal of Hand Surgery (American Volume). 1981, 6: 209-19. 
291 Bronstein AJ, Trumble TE, Tencer AF. The effects of distal radius fracture malalignment on 292 forearm rotation: A cadaveric study. Journal of Hand Surgery (American Volume). 1997, 22A: 258-62.

294 Buchanan TS, Rovai GP, Rymer WZ. Strategies for muscle activation during isometric torque generation at the human elbow. Journal of Neurophysiology. 1989, 62: 1201-12.

296 Bunnell S. Surgery of the hand, 3rd edn. Philadelphia, Pennsylvania, J. B. Lippincott, 1956.

297 Carson RG, Riek S, Smethurst CJ, Párraga JFL, Byblow WD. Neuromuscular-skeletal constraints upon the dynamics of unimanual and bimanual coordination. Experimental Brain Research. 2000, 131: 196-214.

Cooney WP, An K-N, Daube JR, Askew LJ. Electromyographic analysis of the thumb: A study of isometric forces in pinch and grasp. Journal of Hand Surgery (American Volume). 1985,

de Sousa OM, de Moraes JL, Vieira FLdM. Electromyographic study of the brachioradialis 10: $202-10$.

Drake R, Vogl AW, Mitchell AW. Gray's anatomy for students, 1st edn. Philadelphia, Pennsylvania, Churchill Livingstone, 2005.

307 Funk DA, An K-N, Morrey BF, Daube JR. Electromyographic analysis of muscles across the elbow joint. Journal of Orthopaedic Research. 1987, 5: 529-38.

309 Garner BA, Pandy MG. Musculoskeletal model of the upper limb based on the visible human male dataset. Computer Methods in Biomechanics and Biomedical Engineering. 2001, 4: 93 -

312 Geissler WB, Fernandez DL, Lamey DM. Distal radioulnar joint injuries associated with fractures of the distal radius. Clinical Orthopaedics and Related Research. 1996, 327: 135-46. 
314 Gielen CC, van Zuylen EJ. Coordination of arm muscles during flexion and supination:

315 Application of the tensor analysis approach. Neuroscience. 1986, 17: 527-39.

316 Gofton WT, Gordon KD, Dunning CE, Johnson JA, King GJW. Comparison of distal radioulnar

317 joint reconstructions using an active joint motion simulator. Journal of Hand Surgery

318 (American Volume). 2005, 30A: 733-42.

319 Gordon KD, Kedgley AE, Ferreira LM, King GJW, Johnson JA. Design and implementation of an instrumented ulnar head prosthesis to measure loads in vitro. Journal of Biomechanics. 2006, 39: 1335-41.

Gordon KD, Pardo RD, Johnson JA, King GJ, Miller TA. Electromyographic activity and strength

Hagert C-G. The distal radioulnar joint in relation to the whole forearm. Clinical Orthopaedics and during maximum isometric pronation and supination efforts in healthy adults. Journal of Related Research. 1992, 275: 56-64.

Haugstvedt J-R, Berger RA, Berglund LJ. A mechanical study of the moment-forces of the Orthopaedic Research. 2004, 22: 208-13.

Ishii S, Palmer AK, Werner FW, Short WH, Fortino MD. Pressure distribution in the distal supinators and pronators of the forearm. Acta Orthopaedica Scandinavica. 2001, 72: 62934.

Haugstvedt J-R, Berglund LJ, Neale PG, Berger RA. A dynamic simulator to evaluate distal radioulnar joint kinematics. Journal of Biomechanics. 2001, 34: 335-9.

334 Jamison JC, Caldwell GE. Muscle synergies and isometric torque production: Influence of 335 supination and pronation level on elbow flexion. Journal of Neurophysiology. 1993, 70: 947-60. 
Kelly BT, Cooper LW, Kirkendall DT, Speer KP. Technical considerations for electromyographic research on the shoulder. Clinical Orthopaedics and Related Research. 1997, 335: 140-51.

Kendall FP, McCreary EK, Provance PG, Rodgers M, Romani W (Eds.) Muscles: Testing and function, with posture and pain. 5th ed. Baltimore, Maryland, Lippincott Williams \& Wilkins, 2005.

Matsuki KO, Matsuki K, Mu S et al. In vivo 3d kinematics of normal forearms: Analysis of dynamic forearm rotation. Clinical Biomechanics. 2010, 25: 979-83.

Matsuoka J, Berger RA, Berglund LJ, An K-N. An analysis of symmetry of torque strength of the forearm under resisted forearm rotation in normal subjects. Journal of Hand Surgery (American Volume). 2006, 31: 801-5.

Murray WM, Buchanan TS, Delp SL. The isometric functional capacity of muscles that cross the elbow. Journal of Biomechanics. 2000, 33: 943-52.

Naito A, Sun Y-J, Yajima M, Fukamachi H, Ushikoshi K. Electromyographic study of elbow flexors and extensors in a motion of forearm pronation/supination while maintaining elbow flexion in humans. Tohoku Journal of Experimental Medicine. 1998, 186: 267-77.

Naito A, Yajima M, Fukamachi H, Ushikoshi K, Sun YJ, Shimizu Y. Electromyographic (emg) study of the elbow flexors during supination and pronation of the forearm. Tohoku Journal of Experimental Medicine. 1995, 175: 285-8.

Nakamura T, Yabe Y, Horiuchi Y, Yamazaki N. In vivo motion analysis of forearm rotation utilizing magnetic resonance imaging. Clinical Biomechanics. 1999, 14: 315-20.

O'Sullivan LW, Gallwey TJ. Upper-limb surface electro-myography at maximum supination and pronation torques: The effect of elbow and forearm angle. Journal of Electromyography and Kinesiology. 2002, 12: 275-85. 
O'Sullivan LW, Gallwey TJ. Forearm torque strengths and discomfort profiles in pronation and supination. Ergonomics. 2005, 48: 703-21.

362 Perotto AO. Anatomical guide for the electromyographer: The limbs and trunk., 3rd edn. $363 \quad$ Springfield, Illinois, Charles C. Thomas, 1994.

364 Rabischong P. Comprehensive anatomy of motor functions. New York, New York, Springer $365 \quad$ Science \& Business Media, 2014.

366 Rojas-Martínez M, Mañanas MA, Alonso JF. High-density surface emg maps from upper-arm and 367 forearm muscles. Journal of NeuroEngineering and Rehabilitation. 2012, 9: 1-17.

Solomonow M, Baratta R, Bernardi M et al. Surface and wire emg crosstalk in neighbouring muscles. Journal of Electromyography and Kinesiology. 1994, 4: 131-42.

370 Taylor JL, Gandevia SC. A comparison of central aspects of fatigue in submaximal and maximal 371 voluntary contractions. Journal of Applied Physiology. 2008, 104: 542-50.

372 Thompson JC, Netter FH. Netter's concise atlas of orthopaedic anatomy, 1st edn. Teterboro, New 373 Jersey, Icon Learning Systems, 2002.

374 van der Heijden EPA, Hillen B. A two-dimensional kinematic analysis of the distal radioulnar 375 joint. Journal of Hand Surgery (British and European Volume). 1996, 21B: 824-9.

376 van Zuylen EJ, Gielen CC, Denier van der Gon JJ. Coordination and inhomogeneous activation of 377 human arm muscles during isometric torques. Journal of Neurophysiology. 1988, 60: 152348.

379 Werner FW, Palmer AK, Somerset JH et al. Wrist joint motion simulator. Journal of Orthopaedic $380 \quad$ Research. 1996, 14: 639-46.

381 Werner FWM, An K-N. Biomechanics of the elbow and forearm. Hand Clinics. 1994, 10: 357-73. 
382 Winters JM, Kleweno DG. Effect of initial upper-limb alignment on muscle contributions to 383 isometric strength curves. Journal of Biomechanics. 1993, 26: 143-53. 
Table 1. List of muscles included in the study with their abbreviations.

\begin{tabular}{|c|c|}
\hline Abbreviation & Muscle \\
\hline APL & Abductor pollicis longus \\
\hline $\mathrm{BB}$ & Biceps brachii \\
\hline BRA & Brachialis \\
\hline BRAR & Brachioradialis \\
\hline ECRB & Extensor carpi radialis brevis \\
\hline ECRL & Extensor carpi radialis longus \\
\hline $\mathrm{ECU}$ & Extensor carpi ulnaris \\
\hline EIP & Extensor indicis proprius \\
\hline EPL & Extensor pollicis longus \\
\hline FCR & Flexor carpi radialis \\
\hline FCU & Flexor carpi ulnaris \\
\hline PL & Palmaris longus \\
\hline PQ & Pronator quadratus \\
\hline PT & Pronator teres \\
\hline SUP & Supinator \\
\hline
\end{tabular}


Table 2. Muscles and subjects in sub-studies.

\begin{tabular}{ccccccc} 
Group & Muscles & Subjects & Male & Female & Mean Age & Repeats \\
\hline 1 & APL, ECU, FCU & 11 & 7 & 4 & $26.3(2.5)$ & 0 \\
2 & BB, ECRB, EPL, FCR & 11 & 8 & 3 & $25.6(3.2)$ & 6 \\
3 & ECRL, EIP, PT, SUP & 11 & 6 & 5 & $26.5(2.6)$ & 9 \\
4 & BRA, BRAR, PL, PQ & 11 & 6 & 5 & $26.4(3.1)$ & 9 \\
\hline
\end{tabular}


Table 3. Significant differences in muscle activity. Sup indicates significantly more muscle activity when supinating the forearm than pronating. Pro indicates significantly more muscle activity when pronating the forearm than supinating. NS indicates no significant difference in muscle activity when pronating and supinating the forearm.

\begin{tabular}{ccc} 
Muscle & Direction & p-value \\
\hline APL & Sup & $<0.0001$ \\
BB & Sup & $<0.0001$ \\
BRA & Pro & $<0.0001$ \\
BRAR & Pro & 0.0479 \\
ECRB & - & NS \\
ECRL & Pro & 0.0227 \\
ECU & - & NS \\
EIP & - & NS \\
EPL & - & NS \\
FCR & Pro & 0.0103 \\
FCU & - & NS \\
PL & Pro & 0.0056 \\
PQ & Pro & $<0.0001$ \\
PT & Pro & $<0.0001$ \\
SUP & Sup & 0.0042 \\
& &
\end{tabular}


Table 4. Relative activation of muscles when pronating the forearm. Muscles are listed in descending order of activity (highest to lowest) at each forearm position.

\begin{tabular}{|c|c|c|c|c|c|c|c|c|c|}
\hline & Pmax & P75 & P50 & P25 & $\mathbf{N}$ & S25 & S50 & S75 & Smax \\
\hline 1 & PQ & PQ & PQ & PQ & PQ & PL & $\mathrm{PL}$ & PL & $\mathrm{PL}$ \\
\hline 2 & PT & PT & PT & PT & PL & PT & $\mathrm{PT}$ & PQ & FCR \\
\hline 3 & EIP & $\mathrm{ECU}$ & FCR & $\mathrm{ECU}$ & $\mathrm{ECU}$ & PQ & PQ & FCR & ECU \\
\hline 4 & ECU & EIP & ECU & PL & PT & FCR & ECU & ECU & PQ \\
\hline 5 & SUP & SUP & ECRB & FCR & FCR & $\mathrm{ECU}$ & FCR & $\mathrm{PT}$ & $\mathrm{PT}$ \\
\hline 6 & ECRL & EPL & EPL & EIP & ECRB & SUP & SUP & SUP & SUP \\
\hline 7 & EPL & ECRL & PL & SUP & SUP & BRAR & BRAR & BRAR & BRAR \\
\hline 8 & PL & ECRB & EIP & ECRL & ECRL & EIP & APL & ECRB & FCU \\
\hline 9 & APL & APL & APL & ECRB & EIP & ECRL & BRA & BRA & APL \\
\hline 10 & ECRB & PL & ECRL & EPL & EPL & APL & EIP & APL & ECRB \\
\hline 11 & BRA & FCR & SUP & APL & APL & FCU & ECRL & $\mathrm{FCU}$ & ECRL \\
\hline 12 & BRAR & BRAR & BRAR & BRAR & BRAR & ECRB & ECRB & EIP & EIP \\
\hline 13 & FCR & BRA & BRA & BRA & BRA & BRA & FCU & ECRL & BRA \\
\hline 14 & $\mathrm{FCU}$ & FCU & FCU & $\mathrm{FCU}$ & $\mathrm{FCU}$ & EPL & EPL & EPL & EPL \\
\hline 15 & $\mathrm{BB}$ & $\mathrm{BB}$ & $\mathrm{BB}$ & $\mathrm{BB}$ & $\mathrm{BB}$ & $\mathrm{BB}$ & $\mathrm{BB}$ & $\mathrm{BB}$ & $\mathrm{BB}$ \\
\hline
\end{tabular}


Table 5. Relative activation of muscles when supinating the forearm. Muscles are listed in descending order of activity (highest to lowest) at each forearm position.

\begin{tabular}{|c|c|c|c|c|c|c|c|c|c|}
\hline & Pmax & P75 & P50 & P25 & $\mathbf{N}$ & S25 & S50 & S75 & Smax \\
\hline 1 & ECU & ECU & ECU & ECU & SUP & APL & BB & BB & BB \\
\hline 2 & SUP & SUP & $\mathrm{BB}$ & SUP & ECU & SUP & APL & APL & SUP \\
\hline 3 & $\mathrm{BB}$ & APL & SUP & $\mathrm{BB}$ & $\mathrm{BB}$ & $\mathrm{BB}$ & SUP & SUP & APL \\
\hline 4 & APL & BB & APL & APL & APL & ECU & EIP & EPL & ECU \\
\hline 5 & ECRB & ECRB & FCR & ECRB & EPL & EPL & EPL & EIP & EPL \\
\hline 6 & ECRL & PL & ECRB & EPL & EIP & ECRB & $\mathrm{ECU}$ & ECU & EIP \\
\hline 7 & FCU & FCR & EIP & EIP & ECRL & ECRL & ECRB & FCR & FCR \\
\hline 8 & BRAR & ECRL & PL & FCR & ECRB & EIP & PQ & ECRL & ECRL \\
\hline 9 & EPL & BRAR & ECRL & ECRL & PQ & FCR & ECRL & $\mathrm{FCU}$ & FCU \\
\hline 10 & PL & EIP & EPL & PL & FCR & FCU & PL & ECRB & PL \\
\hline 11 & EIP & EPL & BRAR & FCU & BRAR & PL & $\mathrm{FCU}$ & PL & ECRB \\
\hline 12 & FCR & $\mathrm{FCU}$ & $\mathrm{FCU}$ & BRAR & $\mathrm{FCU}$ & PQ & BRA & BRA & PT \\
\hline 13 & PQ & PQ & PQ & PQ & PL & BRAR & FCR & PQ & BRA \\
\hline 14 & BRA & BRA & BRA & BRA & BRA & PT & $\mathrm{PT}$ & $\mathrm{PT}$ & PQ \\
\hline 15 & PT & PT & PT & PT & PT & BRA & BRAR & BRAR & BRAR \\
\hline
\end{tabular}




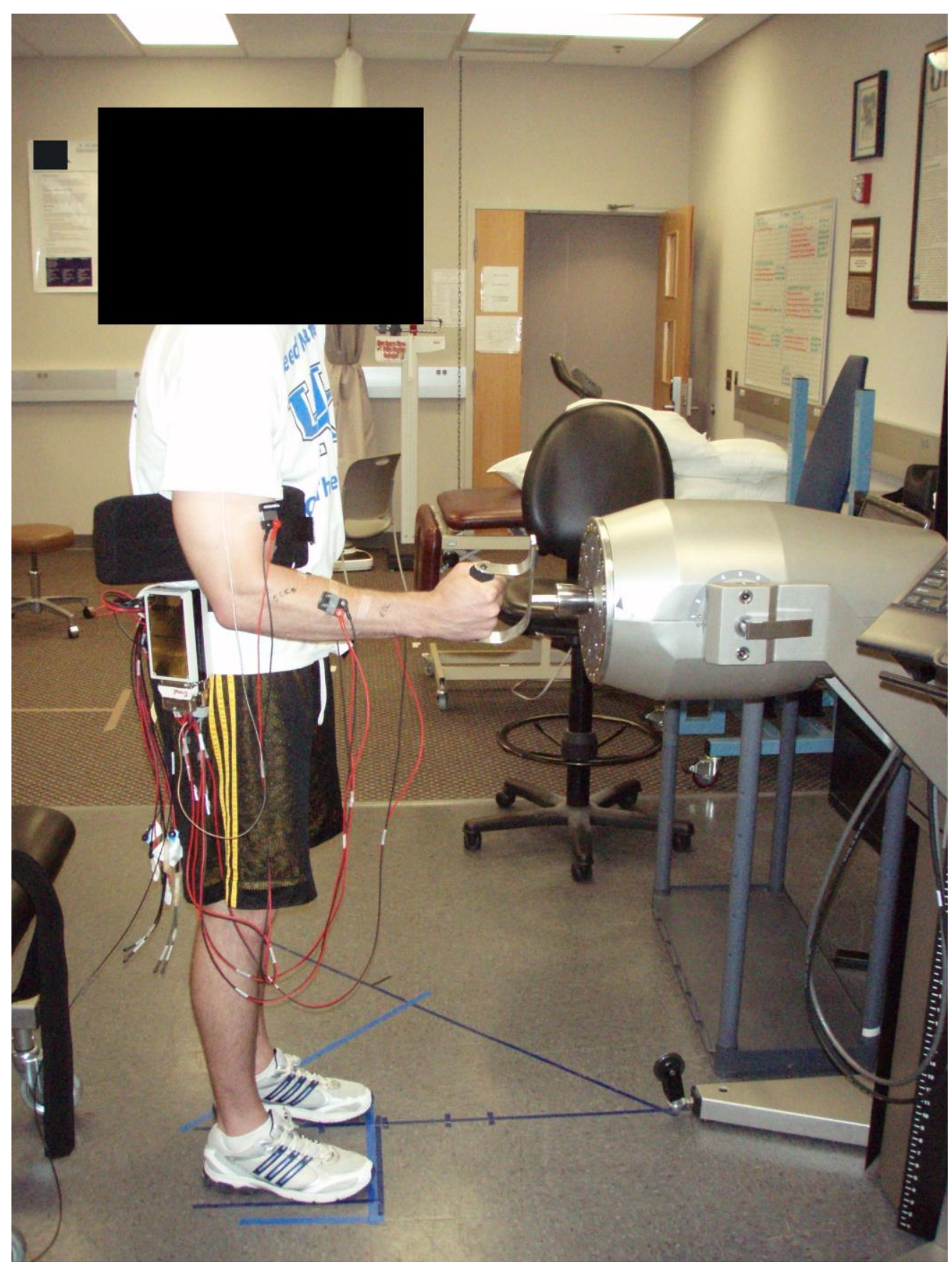

Figure 1. Experimental setup. Subject stood and gripped handle of dynamometer with elbow flexed at $90^{\circ}$. Position of feet was marked and abduction pillow placed under upper arm to standardise posture between trials. 
APL

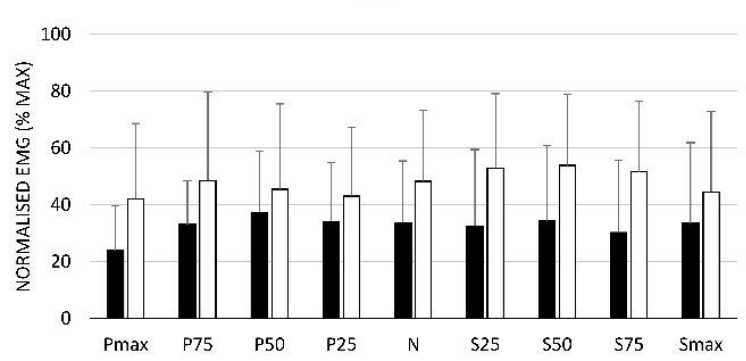

BRA

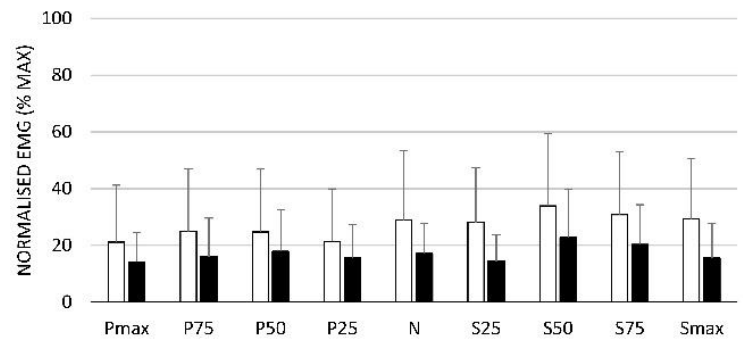

ECRB

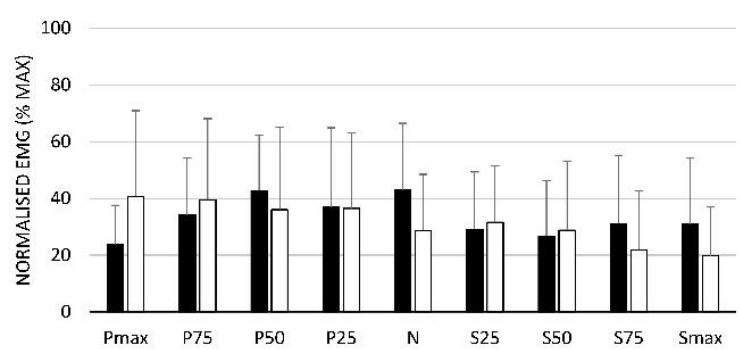

ECU

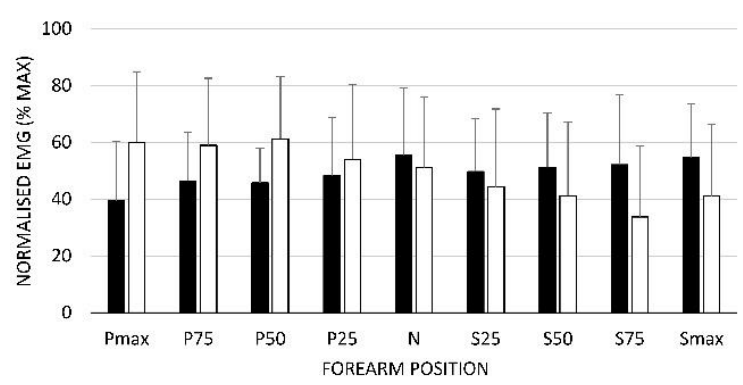

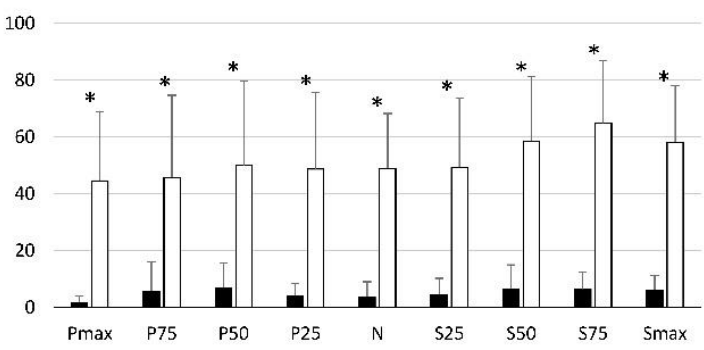

BRAR

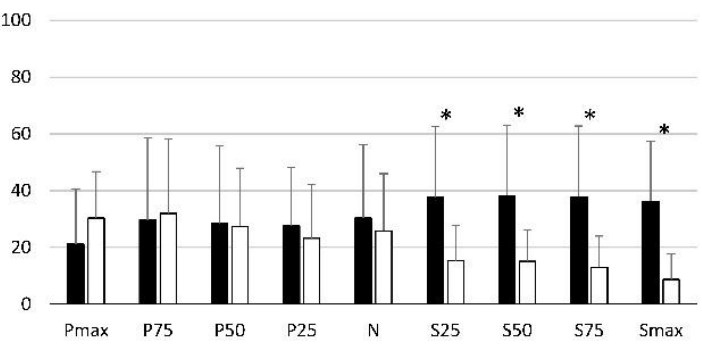

ECRL

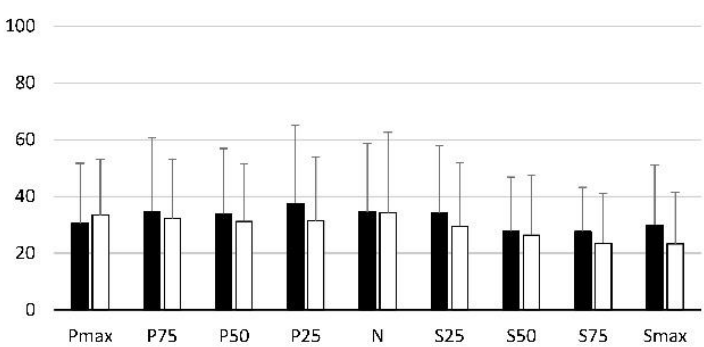

EIP

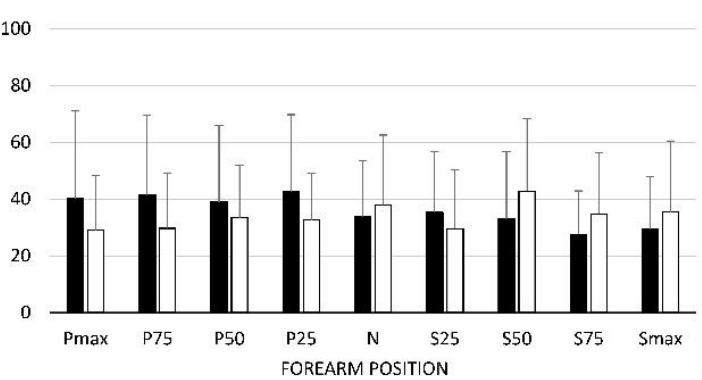

Figure 2. Average, normalised muscle activity during maximum voluntary isometric pronation (black) and supination (white). Error bars represent one standard deviation. * indicates a significant difference $(\mathrm{p}<0.05)$ in muscle activity between pronating and supinating. 

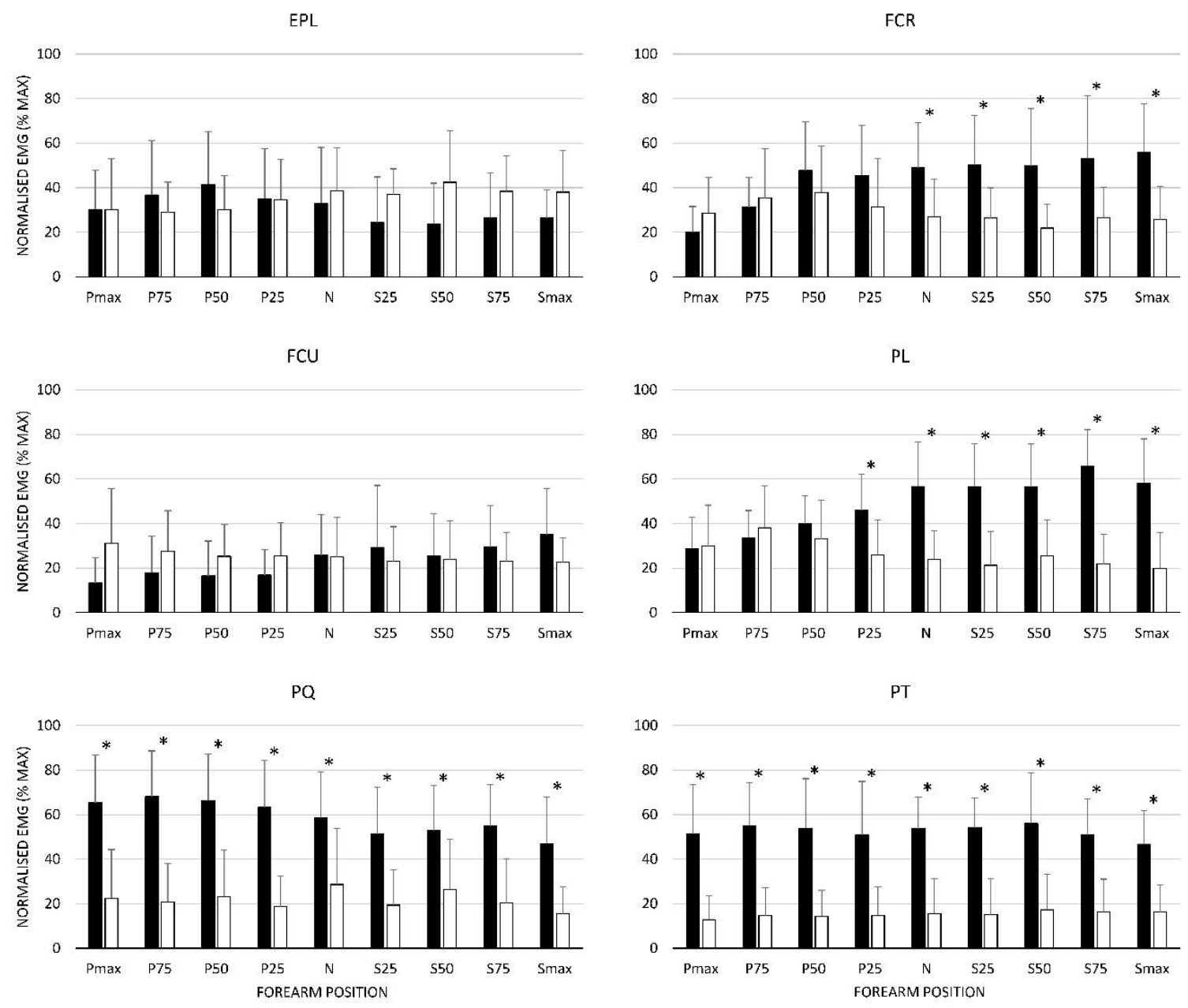

SUP

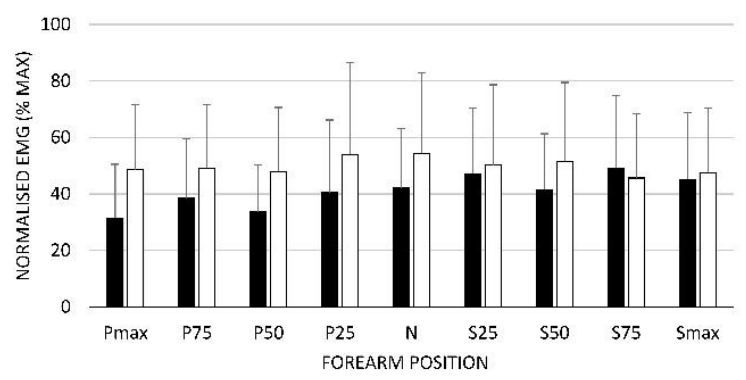

Figure 3. Average, normalised muscle activity during maximum voluntary isometric pronation (black) and supination (white). Error bars represent one standard deviation. * indicates a significant difference $(\mathrm{p}<0.05)$ in muscle activity between pronating and supinating. 